\title{
Construção de Sentidos Apreciativos no Relacionamento Profissional-família na Assistência em Transtornos Alimentares
}

\author{
Laura Vilela e Souza \\ Universidade de São Paulo \\ Manoel Antônio dos Santos \\ Universidade de São Paulo
}

\begin{abstract}
RESUMO
Considerando a pesquisa como intervenção e reconhecendo a importância de se investir no relacionamento profissional-família no contexto da assistência em transtornos alimentares, problematizamos a noção da psicopatogênese familiar e seus efeitos deletérios no vínculo estabelecido pelos profissionais. Neste estudo buscamos descrever e analisar a produção de sentidos apreciativos sobre o relacionamento profissional-usuário, a partir de entrevistas realizadas com familiares de pessoas com transtornos alimentares em atendimento ambulatorial. Participaram dez familiares. A construção do roteiro de entrevistas foi inspirada na abordagem construcionista social da investigação apreciativa. A partir da análise dos sentidos coconstruídos sobre esse relacionamento e dos jogos de posicionamento entrevistadora-familiar, destacamos o questionamento da hierarquia de conhecimento e poder de decisão. Do relacionamento entre profissional e família, evidenciamos o questionamento da neutralidade afetiva, a relevância da clareza das informações fornecidas pelo profissional e a possibilidade de a família contar com espaços de escuta mais amplos no serviço. A implicação para a construção desses sentidos foi destacada.
\end{abstract}

Palavras-chave: relações profissional-família; transtornos alimentares; construcionismo social.

\section{ABSTRACT \\ Appreciative meaning construction in professional-family relationship in the treatment of eating disorders}

Considering research as intervention and recognizing the importance of investing in professionalfamily relationship in the context of assistance in eating disorders, we question the notion of pathogenic family and its deleterious effects in this relationship. This study aims to describe and analyze the appreciative meanings produced about professional-patient relationship by analyzing interviews with family members of people with eating disorders in outpatient care. A total of 10 families were included in the study. The construction of the interview script was inspired by the social constructionist approach of Appreciative Inquiry. The analysis highlighted the meanings and positioning games produced by the questioning of knowledge and decision-making hierarchy between professional and family, the questioning of affective neutrality in this relationship, the importance of clear information given by professional and the possibility of a space for the families to be listen. The implication for construction of these directions was highlighted.

Keywords: professional-family relations; eating disorder; family; social constructionism.

Os manuais de tratamento de usuários de serviços de saúde especializados na assistência em transtornos alimentares (TAs) enfatizam a importância do envolvimento da família no tratamento (American Psychological Association [APA], 2006; National Collaborating Center For Mental Health [NCCMH], 2004). Esse envolvimento é defendido por se considerar que a participação da família aumentaria a efetividade das intervenções oferecidas no contexto do cuidado de usuários diagnosticados com anorexia nervosa (AN) e bulimia nervosa $(\mathrm{BN})$ (Couturier, Isserlin, \& Lock,
2010; Jaeger, Seminotti, \& Falceto, 2011). Todavia, as razões apresentadas para justificar a participação da família no tratamento podem ser bastante distintas entre si.

Souza e Santos (2010) discutem de que modo os familiares constroem seu papel no tratamento. Segundo os autores, dois posicionamentos são comuns nesse cenário: da família como espectadora do tratamento ou da família como parceira dos profissionais na busca da melhora dos sintomas apresentados pelos usuários, como a restrição alimentar radical e a adoção de práticas 
purgativas (vômitos autoinduzidos, ingestão de laxantes, atividade física frenética). Esses dois posicionamentos encontram apoio na literatura da área que, nas últimas décadas, apresentou a relação entre a disfuncionalidade da dinâmica familiar e a etiologia dos TAs (Campos et al., 2012; Silva, 2010). No entanto, atualmente há estudos que criticam essa relação e apostam na família como parceira no tratamento (Souza \& Santos, 2010; Valdanha, Scorsolini-Comin, Peres, \& Santos, 2013).

Em vários países são propostos atendimentos nos quais os familiares estão ativamente engajados no processo de tratamento (Lock, 2010), baseando-se na crítica ao discurso que posiciona a família como "culpada" pelo aparecimento do TA (Eisler, 2013; Le Grange, Crosby, Rathouz, \& Leventhal, 2007). Tierney (2005) justifica a importância da participação da família no tratamento ao considerar a dificuldade do usuário em aceitar o cuidado que lhe é oferecido e por entender que são os pais que deverão oferecer o apoio necessário aos filhos no dia a dia. Todavia, ainda que pareça haver um movimento cada vez maior em defesa da família como fonte potencial de recurso no cuidado à saúde, quando se trata do tratamento de $\mathrm{AN}$ e $\mathrm{BN}$, em muitos momentos a família continua ocupando uma posição passiva nesse cenário relacional.

O relato da história pessoal de Maren Poser (2005), mãe de uma menina de 10 anos diagnosticada com AN, chama a atenção para a necessidade de se repensar o relacionamento profissional-família no contexto de assistência em TAs. Poser relatou que, na primeira internação hospitalar da filha, ninguém esclareceu o que era $\mathrm{AN}$ e que não soube o que fazer quando ela voltou para casa e recomeçou a perder o peso que tinha recuperado no hospital. Relato semelhante foi oferecido por Gráinne Smith (2004), mãe de uma adolescente com AN autora de um livro para auxiliar outros pais e mães com adolescentes com TAs. Smith contou que não percebeu abertura dos profissionais para a conversa, sentindo-se julgada em sua ansiedade com relação ao estado de saúde da filha. Essa familiar concluiu sua reflexão retomando uma ideia consagrada pela literatura das últimas décadas, que advoga que a família da pessoa com AN influencia negativamente seus filhos.

Anderson (1997), ao descrever o atendimento a uma família com duas filhas com AN, apresentou uma carta, escrita pela mãe das meninas, na qual ela descrevia as razões de a terapia familiar não ter sido útil para elas. Nessa carta, a mãe conta como os profissionais que atendiam suas filhas não a escutavam. Quando sua filha mais velha atingiu a maioridade, as raras conversas com os médicos simplesmente deixaram de existir. Para Anderson (1997), essa carta deve servir para reflexão não apenas dos profissionais que trabalham com TA, mas de todos aqueles que oferecem algum tipo de cuidado e que devem buscar atuar de forma colaborativa com usuários e suas famílias.

Considerar a família como capaz de compreender o que é $\mathrm{AN}$ e $\mathrm{BN}$ e reconhecer sua competência para recriar estratégias de tratamento, é coerente com a filosofia recomendada pelo Departamento de Saúde de Londres (DoH, 2001), que menciona que usuário e família devem ser apoiados no desenvolvimento de habilidades para se tornarem especialistas no problema, de modo que possam gerenciar o próprio bem-estar. Portanto, entender de que forma os relacionamentos profissional-família são delineados no contexto de tratamento dos TAs torna-se valioso para a problematização de como a família é posicionada na construção do cuidado em saúde. Nessa direção, o presente estudo teve por objetivo descrever e analisar a produção de sentidos apreciativos sobre o relacionamento profissional-usuário, a partir de entrevistas com os familiares de pessoas com TAs em atendimento hospitalar ambulatorial.

\section{MÉTODO}

\section{Participantes}

Participaram deste estudo 10 familiares de usuários de um serviço hospitalar de assistência em TAs de uma cidade do interior do Estado de São Paulo. Foram eles: Wander, 54 anos, profissional liberal, casado, pai de Lívia, 32 anos, diagnosticada com BN e em tratamento havia sete anos. Lia, 20 anos, estudante, solteira, irmã de Jaqueline, 23 anos, diagnosticada com BN; Iolanda, 47 anos, casada, mãe de Nina, 27 anos, diagnosticada com BN; Mirtes, 42 anos, mãe de Daniele, 18 anos, diagnosticada com AN; Francisco, 19 anos, estudante, namorado de Pietra, 19 anos, diagnosticada com BN; Inácio, 57 anos, pai de Talita, 25 anos, diagnosticada com BN havia cinco anos. Thaís, 40 anos, mãe de Felipa, 19 anos, diagnosticada com AN e recentemente admitida no serviço; Sílvia, 43 anos, mãe de Nicole, 15 anos, diagnosticada com AN. Bernadete, 50 anos, mãe de Paula, 27 anos, diagnosticada com BN; Márcia, 46 anos, mãe de Gislaine, 20 anos, diagnosticada com BN.

\section{Instrumentos}

O discurso construcionista social leva em considera- 
ção a pesquisa como intervenção, entendendo-a como oportunidade não de descobrimento de fatos e realidades, mas de invenção de fatos e criação de realidades. Essa postura filosófica questiona as noções de neutralidade, generalização, objetividade e a separação sujeitoobjeto em ciência e entende que qualquer pesquisa colabora na produção dos "dados" que estuda (McNamee \& Hosking, 2012; Spink \& Medrado, 2013). A proposição de pesquisas que favoreçam a construção de cenários úteis para a população envolvida é um uso ético e político do pesquisar na produção de realidades alternativas. A abordagem da investigação apreciativa (IA) aposta justamente nessa criação de realidades alternativas, a partir da proposição de pesquisas com o foco nos recursos de que as pessoas, grupos, comunidades e instituições já são detentores, evitando questionamentos que enfatizem realidades problemáticas e resgatando o que é tomado como positivo com relação ao aspecto investigado (Souza, McNamee, \& Santos, 2009). Entende-se que as respostas às perguntas apreciativas não são a descrição de como as coisas são com relação ao objeto de estudo, mas justamente a oportunidade de cocriação de sentidos em direção ao que se quer que ele se torne.

Desse modo, no presente estudo, ao tomarmos o relacionamento profissional-família como objeto de investigação, apostamos no questionamento dos familiares de pessoas diagnosticadas com TAs sobre sua relação com os profissionais no contexto de assistência hospitalar, a partir da problematização do que eles consideram útil, funcional, positivo e apreciado nesse relacionamento. Essa escolha se justifica pelo reconhecimento, encontrado na literatura da área, dos efeitos negativos sobre o relacionamento profissionalfamília das teorias que descrevem essas famílias como disfuncionais ou psicopatogênicas. Apostar no relato de experiências positivas vividas por familiares nesses relacionamentos é investir, precisamente, em formas alternativas de construção dessa relação, oferecendo recursos para que possamos pensar esse relacionamento a partir de outros parâmetros e possibilidades. Como apontado por Souza et al. (2009), um estudo apreciativo não é sinônimo de ignorar os problemas, dificuldades ou desafios do cenário estudado, mas, sim, entender que tais dilemas podem ser melhor enfrentados justamente pelo favorecimento de formas de se lidar com eles.

O roteiro de entrevista construído para esse estudo abordava, para além dos aspectos positivos no relacio- namento profissional-família, as histórias apreciativas com relação ao familiar diagnosticado com $\mathrm{AN}$ ou $\mathrm{BN}$, o momento de chegada ao serviço, a experiência de internação hospitalar, as melhoras vividas e a descrição de um futuro considerado ideal para a família e para a assistência em TAs. Essas perguntas respondiam aos objetivos de uma investigação mais ampla realizada.

\section{Procedimento}

A seleção dos participantes em uma pesquisa apreciativa oferece a oportunidade de convidar, intencionalmente, pessoas que ocupem lugares privilegiados na recuperação do que é considerado funcional no contexto estudado (Reed, 2007). No presente estudo, essa intencionalidade refere-se ao convite para a participação na investigação dos familiares mais assíduos no serviço e que frequentavam o grupo de apoio a eles destinado, uma vez que considerávamos que eles possuiriam mais histórias para compartilhar sobre essas relações. Levando-se em conta esse aspecto e entendendo que nem todos os familiares convidados concordaram em participar da pesquisa, podemos formular a hipotése de que os participantes deste estudo estavam mais disponíveis para abordar as questões positivas desses relacionamentos. Assim, não ignoramos o fato de que críticas e denúncias às dificuldades vivenciadas nesses relacionamentos podem ter ficado de fora se pensarmos em possíveis relatos que os familiares não assíduos ao atendimento e não participantes do grupo poderiam abordar.

Outro aspecto relevante de ser mencionado foi o fato de que a entrevistadora envolvida no estudo era também psicóloga voluntária do serviço, além de ter ocupado a posição de coordenadora do grupo de apoio aos familiares. Essa relação prévia foi por nós considerada uma oportunidade para que os familiares se sentissem à vontade para as conversações. A partir do convite feito pelo discurso construcionista social, compreendemos que não há uma relação ideal ou neutra entre pesquisador e pesquisado. Como mencionado por Spink e Lima (2013), o rigor na pesquisa construcionista se dá pela explicitação e visibilidade das decisões, passos, relações de poder, potenciais e impedimentos na pesquisa. Portanto, entendemos que os resultados produzidos devem ser contextualizados a partir desses circunscritores que delimitam a interação entrevistadora-familiar e as conversas empreendidas.

As entrevistas individuais foram realizadas em sala reservada do serviço, audiogravadas com o uso de aparelho digital em formato $\mathrm{mp} 3 \mathrm{e}$ transcritas na íntegra e 
literalmente. Para os propósitos deste estudo, selecionamos os momentos das entrevistas nos quais os familiares responderam à pergunta: "Pense em um profissional com o qual você tenha uma relação muito positiva. Descreva como é essa relação", deixando de fora de nossa análise os momentos da entrevista nos quais outros focos de conversa foram abordados.

Entendemos que esse recorte necessário impede a apresentação ao leitor do dinamismo e processualidade da produção de sentidos de toda a entrevista. Todavia, buscamos essa contextualização por meio da análise dos jogos de posicionamentos entrevistadora-entrevistado (Langenhove \& Harré, 1999). Na apresentação dos resultados, destacamos os trechos de falas dos familiares que foram foco da discussão, que é empreendida posteriormente.

\section{Cuidados éticos}

$\mathrm{O}$ projeto que deu origem a este relato de pesquisa foi aprovado pelo Comitê de Ética em Pesquisa da instituição na qual o estudo foi desenvolvido (Protocolo $n^{\circ}$ 7310/2007). Os familiares formalizaram sua anuência por meio da assinatura do Termo de Consentimento Livre e Esclarecido. Foram utilizados nomes fictícios para os familiares e para os profissionais por eles mencionados durante as entrevistas.

\section{Co-construindo com os familiares os resultados da pesquisa}

Wander era assíduo frequentador do grupo de apoio psicológico e sempre oferecia apoio aos pais e mães iniciantes, destacando os ganhos obtidos por sua filha no decorrer do tratamento. Sobre os profissionais que Wander considerava que mais o ajudaram na longa trajetória de tratamento de sua filha, mencionou a importância das psicólogas coordenadoras do grupo de apoio. $\mathrm{O}$ jogo de posicionamento aqui definido foi o de profissional competente e pai agradecido. Após Wander responder à pergunta da entrevistadora afirmando que tinha boa relação com as psicólogas do grupo, a entrevistadora, então, pediu a ele que dissesse o que esse relacionamento tinha de especial.

Wander: "Eu acho assim: todo o trabalho de vocês [profissionais] passa muita segurança pra gente, assim, pelo carinho, pelo posicionamento, pela seriedade, entendeu? É tratado o paciente aqui no hospital, nos passa muita segurança, passa muita segurança. A impressão é que, quando a gente chega aqui, que a gente não é aquela relação de pais ou paciente, entendeu, de médico. Não!"

Lia comparecia semanalmente ao grupo de apoio psicológico, buscando entender a razão de tanto sofri- mento pelo qual a irmã passava. Jaqueline, em diferentes momentos, apresentou alguns comportamentos autodestrutivos muito graves, inclusive com risco de morte. As duas irmãs mantinham uma relação de bastante proximidade e Lia buscava ser uma fonte de apoio. $\mathrm{Na}$ época da entrevista, Lia era atendida em psicoterapia individual por outra psicóloga do serviço. Ela disse entender a entrevista como a chance de transmitir sua experiência para ajudar outras pessoas, como a irmã dela. O jogo de posicionamento aqui empreendido foi o de entrevistadora interessada em melhorar o serviço e irmã que colaborava para essa melhoria.

Ao responder sobre o profissional com quem mantinha uma boa relação, Lia mencionou a psicóloga que a atendia individualmente.

Lia: "Eles [categoria de psicólogos] nos ajudam a entender que esse momento... que você não é a única pessoa que tá passando esse momento. Eu sei que os psicólogos não passaram por isso, mas eles, eles tentam ajudar você a entender o que você está passando. Eles não passaram, mas te fazem entender o que você está passando. Eles tentam te fazer entender o que você tá passando e as pessoas, o próprio ser humano, mostram que você não tá sozinha. Que eles tão ali pra lutar com você, sabe?"

Iolanda era dona de casa e tinha muita dificuldade em lidar com as crises alimentares compulsivas da filha, que chegava a acarretar prejuízos financeiros por conta da quantidade de alimentos ingeridos. Indignada, a mãe contava, com muito sofrimento, como tentara, por meio da força física, impedir a filha de entrar no banheiro para vomitar. Quando Iolanda foi entrevistada, Nina estava sob cuidados no serviço havia aproximadamente um ano. Em todo retorno de Nina ao serviço, Iolanda a acompanhava e frequentava o grupo de apoio.

Quando conversava sobre as experiências positivas que vivenciara com profissionais do serviço, Iolanda destacou que um bom profissional tem que conversar de forma firme, pontuando os perigos da $\mathrm{AN}$ e da BN. Em seguida, Iolanda afirmou várias vezes que essa conversa deveria ser realizada pelos profissionais na presença de toda a família da pessoa acometida. A entrevistadora buscou entender, então, se Iolanda estava construindo o pleito de maior proximidade do familiar com os profissionais que atendiam sua filha - que não eram, necessariamente, os mesmos com quem ela mantinha contato direto nos grupos de apoio aos familiares. Nesse jogo de posicionamentos, definiram-se uma entrevistadora que queria ouvir a opinião dos familiares sobre o serviço e uma mãe que fazia um pedido de mudança:

Entrevistadora:" Você sente falta do contato com os profissio- 
nais? Não da gente lá do grupo. Você sente falta de conversar mais com quem atende a Nina?"

Iolanda: "Sim, porque ela passa lá [nos atendimentos exclusivos dos pacientes], e a gente passa aqui [nos grupos de familiares], aí ela passa lá com o médico e a gente vai embora. Então, eles [psicólogos, nutricionistas e médicos que sua filha sem a presença da família] poderiam orientar mais a gente como a gente deve agir, como a gente deve fazer. Isso é o mais importante, mesmo que seja uma salinha pequena [de atendimento], mas que tenha mais acompanhamento. Todos juntos assim na busca de uma cura, porque ela precisa se livrar disso daí."

Daniele, filha de Mirtes, estava em um momento de franca melhora em relação aos sintomas do TA, ainda que a mãe avaliasse que essa melhora não se estendia ao bem-estar psicológico da filha. Ao falar de uma relação positiva com um profissional, Mirtes enfatizou o fato de ser possível criar vínculos entre família e profissional do serviço e discorreu sobre o que considerava necessário para que essa relação fosse satisfatória. Esse posicionamento de Mirtes como alguém que devia receber o tratamento oferecido delineava os contornos de sua relação com a entrevistadora, em um jogo de posicionamento entre uma entrevistadora que oferecia algo de bom e Mirtes, que deveria receber passivamente essa dádiva.

Mirtes: "Pra mim, pra facilitar a relação é [a família] comparecer ao serviço que eles [profissionais] oferecem e eles oferecem o serviço pra gente. Então, ele [profissional] tá aqui pra oferecer o serviço, e a gente tá aqui pra aproveitar essa oferenda, digamos assim, que é feita pelos profissionais."

Francisco tinha participado de alguns encontros do grupo e havia pouco tempo vinha acompanhando Pietra em seus retornos ambulatoriais. Ele pontuou que gostou muito de ter conversado individualmente com alguns profissionais que atendiam sua namorada:

Francisco: "Tá vindo, conversando individualmente. Eu gostei disso, você poder ter uma relação mais aberta com o profissional."

\section{Entrevistadora:"O que aconteceu para tornar isso possível?"}

Francisco: "Foi eu ter.. Na realidade, chegado nele [médico que atendia Pietra] e falado: 'Olha, eu não gostei desse problema!' ou: 'Esse tratamento não está fazendo efeito'. Procurar ter uma relação mais aberta, porque muitas vezes a pessoa que está doente não quer falar abertamente do medicamento, ter um tempo mais disponível com o médico, responsável pela paciente pra você poder se abrir."

Entrevistadora: "E o que o profissional teve que fazer pra tornar isso possível?"

Francisco: "Ter tempo disponível para ouvir a gente."

Inácio era comerciante e teve dificuldade em aceitar o diagnóstico da filha, chegando a proibi-la de comer para evitar que vomitasse. No grupo de apoio psicoló- gico, Inácio era um pai bastante benquisto e encontrava espaço para expor suas dúvidas em relação aos comportamentos de sua filha. Ele não se mostrava convencido de que seriam manifestações de "doença" ou de "frescura". Ao responder à questão que o instava a falar de um relacionamento que ele considerava positivo com algum profissional do serviço, contou:

Inácio:" Olha, se eu te falar, eu não consigo destacar ninguém. Para mim todos [profissionais] tiveram um papel fundamental no tratamento dela até hoje. A ajuda em si, acolhendo. A hora que você precisava, a gente sempre teve aqui um apoio. Eu sei que tudo ajudou muito, tudo. Foi muito boa a recepção, né? Porque a gente nunca escutou assim, digamos, uma resposta nervosa do médico, seja lá quem for. Nunca."

Além disso, Inácio pontuou a importância de o médico se dispor a não apenas ouvir a filha, mas incluir também os pais, considerando-se que a filha, em muitos momentos, n'ão contava a verdade para a profissional que a atendi: Para relatar às vezes muito problema que a filha não... No caso da Talita não contava, né?". Inácio se colocava na entrevista como alguém que se surpreendia com uma postura adequada do profissional e que se sentia à vontade para fazer uma sugestão de mudança na forma de atendimento dos profissionais.

Thaís era dona de casa e participava dos grupos sempre que podia, uma vez que morava em uma cidade situada a mais de $600 \mathrm{~km}$ do local de atendimento. Sua participação no grupo era muito valorizada pelos demais familiares e coordenadores, não apenas por seu jeito humilde, inteligente e simpático de conversar, mas pelo fato de ter uma história de muito sucesso no tratamento, marcada pela superação. A interação de Thaís com a entrevistadora se deu a partir do posicionamento de ambas como pessoas orgulhosas da sua superação da primeira. Quando a entrevistadora pediu para Thaís destacar o que ajudava a manter uma boa relação com o profissional, ela respondeu:

Thaís: "Eu acho assim, que o que ajudou foi... Assim, acho que um pouco foi o carinho e assim... Vocês [coordenadoras do grupo de apoio] pedirem para a gente participar dos grupos, para a gente vir, né? Isso assim, no começo, fez receber bastante força. Acho que isso também ajudou muito, porque eu aprendi muito no grupo, com as pessoas, com os psicólogos, a lidar com as doenças. Ali ajudava na espera, na força."

Após essa declaração a entrevistadora emendou a pergunta:

Entrevistadora: "Algum momento te marcou mais? A fala de algum profissional?"

Thaís: "Teve esse psiquiatra, que ele falou: 'Nossa, a Felipa deu uma melhorada boa'. E quando o médico fala isso pra gente... Nossa! Ai eu estava supercontente! Assim, de o psiquiatra, a nutricionista, o psicólogo falar: 'A Felipa está melhorando bas- 
tante'. Então eu acho que isso aí, para a gente, é uma vitória, né?"

Sílvia era casada, dona de casa e participava dos grupos destinados aos familiares havia cerca de um ano, desde o início do tratamento de sua filha. Ela contou à entrevistadora como sentia falta de que as conversas dos profissionais com os familiares pudessem ser mais claras em termos do que é o TA, seus riscos e possibilidades de tratamento, engajando-se em um jogo de posicionamento entre uma entrevistadora disponível para ouvir possíveis reclamações sobre o serviço, ainda que buscasse pelo que era considerado positivo, e uma familiar que confiava a essa profissional suas sugestões de melhoria:

Sílvia: "Eu acho que quanto mais claro, melhor, né? O profissional falar claramente: 'Olha, pode tá acontecendo isso, isso e isso'. Informar melhor os pais, porque, na verdade, tudo o que aconteceu na minha vida, eu não fui muito bem informada com os meus filhos, tudo. Falar do tratamento, o que pode ser feito. Falar: 'E uma doença emocional, é da família, ou não sabemos'."

Bernadete recordou o primeiro contato que teve com um profissional que diagnosticara o TA, reputando-o como um momento positivo:

Bernadete: "Ele primeiro atendeu a Paula. Foi [ele] que mostrou o caminho aqui para nós. Porque a gente fica assim perturbado quando você vê que a pessoa está com isso [BN], sabe? Você tem que procurar uma ajuda, né? Então aí, nossa! Eu fiquei assim tão descontrolada, que eu falei: 'Meu Deus, dá uma luz para a gente'. E aí então que nós viemos aqui, o doutor Vieira [nutrólogo, nome fictício] que olhou pela primeira vez. Aí que nós começamos a passar, né, a fazer o tratamento aqui."

Bernadete ressaltou que o encontro com o doutor Vieira marcou, para a família, a possibilidade de cuidado da filha. Também contou que toda a orientação recebida naquele momento de chegada ao serviço foi muito útil, em um jogo de posicionamento com a entrevistadora, como uma mãe agradecida por sua chegada ao serviço.

Márcia era comerciante, casada e frequentava o grupo de apoio sempre que seu trabalho permitia. No momento da entrevista, sua filha encontrava-se em franca recuperação. Márcia contou que o profissional que mais a ajudara foi o psiquiatra, que explicou o diagnóstico de sua filha:

Márcia: "Porque ele sentou, conversou, explicou".

Entrevistadora: "O que você acha que era...? Era o jeito dele?"

Márcia: O jeito dele conversar, porque ele não passou a mão na cabeça dela [filha], ele foi direto. Ele não falou: "Você não vai morrer..." Ele falou que, se ela continuasse vomitando, ela ia morrer mesmo. Quer dizer... Ela colocou aquilo na cabeça e falou: "Mãe, eu não quero morrer...". Quando é o médico falando,

\section{a paciente confia mais}

Márcia se apresentava à entrevistadora a partir da posição de dependente do profissional, e de sua explicação para o TA, para convencer a filha a se cuidar.

\section{Tecendo possibilidades de discussão}

Como visto na tessitura dos resultados, os familiares abordaram, na interação com a entrevistadora: a possibilidade de sair de uma relação rígida e hierarquizada com o profissional; a importância de o profissional colocar-se ao lado da família, ainda que não estivesse passando pela mesma situação que ela; o benefício da oferta de espaços de escuta genuína e apoio maciço, especialmente no início do tratamento; o uso da autoridade profissional como forma de ajudar a filha a entender os riscos a que está exposta; o pedido de maior participação dos familiares no espaço de consultas das filhas; a possibilidade de o profissional ofertar o cuidado e a família saber aproveitá-lo; a possibilidade de a família poder falar abertamente com o profissional sobre o que não considera bom ou adequado no tratamento; a valorização de uma postura profissional acolhedora e respeitosa; a importância de o profissional ter abertura para ouvir pais e mães, entendendo que eles podem ter uma versão diferente para contar, em contraste com a apresentada pelas filhas para justificar seus comportamentos sintomáticos; o valor positivo do grupo de apoio psicológico como fonte de informação sobre a melhor conduta a ser tomada em relação à perturbação alimentar; a importância de receber feedback constante do profissional sobre a melhora das filhas; a necessidade de o profissional explicar com clareza o que é AN e $\mathrm{BN}$; o alívio experimentado ao encontrar um profissional que indique um tratamento especializado; a importância das orientações dos nutricionistas; a relevância das palavras de apoio do psicólogo; e a importância de o profissional ser franco e direto em relação aos reais perigos associados aos TAs. Esses são sentidos tecidos no contexto dos TAs, mas que em muitos aspectos se articulam a outros contextos de assistência em saúde, a partir da valorização, pedidos de mudança e sugestões de mudanças no relacionamento profissional-família.

$\mathrm{Na}$ análise desses sentidos co-produzidos nas entrevistas e dos jogos de posicionamento deles derivados, podemos perceber a influência exercida por alguns discursos tradicionais em saúde nas falas dos familiares. Wander valoriza o fato de os profissionais cultivarem uma relação de proximidade com ele, o que o faz sentir que são todos de "uma mesma família". Tradicional- 
mente, o discurso da neutralidade afetiva marca as práticas profissionais, sob a justificativa racional de que um vínculo afetivo profissional-usuário-família poderia interferir negativamente na objetividade da avaliação e, por conseguinte, na conduta profissional em relação à correta condução do tratamento. Nesse tipo de discurso, o jogo de posicionamento entre profissional e família é, usualmente, marcado por um profissional especialista no TA e um familiar que precisa ser informado sobre o que é o transtorno, a necessidade de engajar-se em um tratamento e como ele deve ser feito, posicionamentos que têm sido questionados pela literatura recente da área, como mencionado anteriormente (APA, 2006; DoH, 2001). Quando, considerando-se o longo tempo médio de tratamento, pensamos que muitas famílias passarão anos convivendo com os mesmos profissionais, que muitas vezes representam sua única fonte de apoio, problematizar os efeitos e repercussões desse discurso na construção do relacionamento profissionalfamília é fundamental. A categoria objetividade é valorizada a partir de uma inteligibilidade que defende a ciência como um esforço de descoberta de verdades. Inteligibilidades distintas, como a proposta pelo discurso construcionista social, entendem a ciência como construção de verdades locais e provisórias (McNamee \& Hosking, 2012). Assim, a objetividade pode dar lugar à autorreflexividade, que tem sido definida como o esforço do profissional em analisar suas práticas a partir de sua utilidade, ou seja, a proximidade afetiva (o carinho mencionado por Thaís) não é um atributo valorizado como bom ou ruim a priori, mas um sentido coconstruído dependendo dos seus efeitos no cenário relacional de cada família.

Outro tradicional discurso em saúde pode ser identificado na fala de Lia: o da hierarquia rigidamente instituída entre profissional e usuário. $\mathrm{O}$ jogo de posicionamento é de um profissional que detém um saber especializado sobre a situação (TA) e uma família que passa pela situação sem dominar um saber que possa ser instrumentalizado para lidar com suas atribulações (Souza \& Santos, 2010). Nesse caso, a diferença instituída pode afastar o profissional da família ou impedir o estabelecimento de um vínculo de empatia entre eles. Além disso, essa hierarquia pode coibir o posicionamento da família como especialista no assunto, a partir de sentidos e lógicas distintos daqueles que ordenam o conhecimento científico. Lia não reconheceu esses possíveis efeitos negativos em seus relacionamentos com os profissionais. Ela afirma que não ser "um igual", nesses casos, pode fazer com que o profissional ajude mesmo não tendo passado pela mesma situação. Além disso, essa possibilidade de escuta oferecida por alguém externo ao núcleo familiar parece ter sido importante, uma vez que Lia não identificava fontes de apoio em seus familiares. Uma observação deve ser feita com relação a esse aspecto, questionando-se em que medida a oferta de espaços de apoio e escuta profissional pode inibir o investimento no fortalecimento das redes de apoio aos familiares em suas comunidades de origem., ou seja, em que medida a oferta do tratamento coloca apenas sobre o profissional a fonte de resolução de problemas. Quando pensamos no empoderamento de pais e mães como responsáveis pelo cuidado da filha no dia a dia - e, portanto, fora da situação de tratamento, como pontua Tierney (2005) - , trabalhar na construção e no fortalecimento dessas redes pode ser importante.

A narrativa de Iolanda se aproximou muito da experiência relatada por Smith (2004), da família que se sente excluída das consultas ambulatoriais de suas filhas. A princípio, o principal argumento para a família não participar dos atendimentos com psicólogas, nutricionistas e médicos é o respeito à privacidade das informações sobre o tratamento, quando as usuárias atendidas são maiores de 18 anos (Treasure, Whitaker, Whitney, \& Schmidt, 2005), como mencionado por Iolanda. O que Iolanda e outros pais e mães parecem pleitear é um espaço de orientação e conversa que leve em conta seu protagonismo no cuidado de suas filhas. Quando pensamos no interesse comum entre profissionais, familiares e usuários de estabelecer boas relações e poder criar estratégias saudáveis para lidar com o TA, o foco pode ser deslocado da ideia de um profissional eticamente impedido de passar informações para os familiares, para um profissional atento às possíveis conversas que podem envolver toda a família.

Também na fala de Inácio é possível identificar o pedido de maior proximidade e abertura para o diálogo entre familiares e profissionais. Pesquisadores apontam que, mesmo que a princípio o usuário adulto sinta-se receoso com a presença de familiares nos atendimentos, quando percebe que a participação da família tem um caráter colaborativo, esse adulto mostra-se aberto e se beneficia do apoio familiar. Muitas vezes, os usuários se sentem culpados pelo sofrimento causado a seus familiares e acreditam que não envolver a família nos atendimentos pode poupá-los de mais dor $(\mathrm{NCCMH}$, 2004). Por essas razões, os pesquisadores defendem que a participação da família deve ser negociada de forma aberta e transparente, caso a caso, esmerando-se para construir vínculos de confiança entre todos, profissio- 
nais, usuários e familiares. Nesse anseio de transparência, é possível que o medo do pai ou da mãe de que a filha esteja mentindo possa aparecer de forma não acusativa, mas com o sentido de preocupação e cuidado.

Mirtes afirmou que uma boa relação com o profissional é fruto da atitude do familiar de aproveitar o que é oferecido pelo profissional. Com base nisso, podemos pensar no jogo de posicionamentos de um trabalhador de saúde ativo, que oferece o cuidado, e de um familiar passivo, que tem como responsabilidade apenas receber esse cuidado. Uma das principais dificuldades na manutenção desse jogo, mencionada por Fleminger (2005), é que muitos pais e mães, que depositam exclusivamente nos profissionais a responsabilidade pelo êxito do tratamento, acabam se decepcionando com os resultados alcançados, o que leva a altas prematuras e índice elevado de abandono do tratamento. É importante ressaltar que nesse jogo de posicionamentos está implicado o discurso tradicional em saúde, que fixa os profissionais como detentores de um saber privilegiado sobre o que é o TA e sobre o que é necessário fazer para tratá-lo, ou seja, como já mencionado, as práticas em saúde que legitimam tal discurso propagam o sentido do TA como uma "entidade nosológica", que só pode ser identificada, descrita e compreendida por uma categoria específica, a dos profissionais.

Muitos são os relatos de familiares sobre o desconhecimento do que é $\mathrm{AN}$ e BN e, como consequência, a confissão recorrente de sua impotência em relação ao que fazer para ajudar seus membros que estão em situação de intenso sofrimento. Honey e Halse (2005) mostraram como a construção que pais e mães elaboram sobre o que é o TA influencia a maneira como respondem e se relacionam com suas filhas. O TA pode ser tomado como uma doença, como um problema psicológico, como uma escolha ou como um mistério. A cada sentido coconstruído diferenças no relacionamento profissional-família se delineiam. Os autores concluem que o profissional que busca entender como os familiares constroem o que é o problema alimentar tem mais condições de obter a colaboração da família no tratamento.

O valor que Thaís dá às falas apreciativas dos profissionais pode ser discutido, relacionando-o com as teorias que apontam a família (basicamente os pais) como responsável pelo aparecimento de $\mathrm{AN}$ e BN, especialmente as teorias de culpabilização da mãe. Sendo assim, o profissional pode se mostrar sensível a esses efeitos negativos e reforçar, em seus diálogos com a fa- mília, o posicionamento dela como parceira no tratamento, e não como resistência e obstáculo (Anderson, 1997; Souza \& Santos, 2009).

Como discutido, quando o TA é definido como o problema a ser tratado, a família deixa de ser protagonista do cuidado, uma vez que pouco conhece sobre $\mathrm{AN}$ e BN do ponto de vista clínico, nutricional ou psicológico. Sendo assim, é interessante contextualizar a fala de Sílvia, Bernadete, Márcia e Thaís nesse cenário relacional marcado pelo desespero da família por não entender o que está acontecendo com um de seus membros e por necessitar do feedback do profissional sobre o progresso do tratamento, geralmente prolongado. Nesse cenário, constrói-se o sentimento de alívio, pelo encontro de um profissional que acerta o diagnóstico e pela indicação de um tratamento especializado, além da necessidade de orientações claras sobre o que é o transtorno e o que deve ser feito para enfrentá-lo. A partir da fala de Márcia, por exemplo, podemos refletir sobre a autoridade profissional: ela é tomada como positiva, pois, socialmente, sua palavra é valorizada e pode direcionar o modo de agir da família, legitimando determinados caminhos. Thaís também menciona a dependência da avaliação profissional para que possa se tranquilizar em relação à saúde da filha.

A fala de Francisco remete à possibilidade de que, ainda que a situação seja definida como um problema médico, a família possa se sentir autorizada e empoderada para discordar da avaliação e da conduta do profissional do serviço. Importa ressaltar que tal posicionamento, de alguém que é capaz de abordar o profissional e criticar seu atendimento, parte de um namorado e não de um pai ou mãe entrevistados. Podemos formular a hipótese de que tal comportamento derive do fato de os pais, ao serem tomados como responsáveis pelo adoecimento das filhas, se coloquem em uma posição mais passiva e dependente com relação ao comportamento dos profissionais.

Para que um posicionamento de crítica seja possível, Tierney (2005) e Poser (2005) defendem que a família deve mergulhar no universo discursivo dos profissionais, de modo a poder conversar de modo mais igualitário sobre essas questões, ou seja, seria essa a possibilidade de se aproximar de relações profissionalusuário mais horizontais, tal como almejado na filosofia que sustenta o Sistema Único de Saúde brasileiro (Brasil, 2009). Todavia, entendemos que esse ainda é um grande obstáculo a ser ultrapassado, uma vez que, da forma como as práticas em saúde são, muitas vezes 
implementadas, constrói-se e mantém-se uma rígida relação de poder entre um profissional que detém o condão de tomar decisões no tratamento e um usuário que pode, no máximo, criticá-lo.

A partir do discurso construcionista social, podemos nos perguntar quais seriam os efeitos de uma negociação profissional-família que não apenas tomasse como base a verdade médica, mas que também permitisse que diferentes verdades sobre a situação pudessem ser sustentadas e igualmente validadas como versões possíveis, ou seja, conhecimentos derivados de discursos do senso comum ou explicações religiosas, sobre o que estaria acontecendo com o usuário, poderiam entrar em cena e participar da elaboração de um plano de tratamento aberto à exploração dos benefícios de outros conhecimentos produzidos em saúde. $\mathrm{Na}$ verdade, não seria com surpresa e contentamento que Inácio receberia "uma resposta nervosa do médico". Prece ser justamente o contrário. Esse ainda é um desafio a ser enfrentado.

\section{Convidando à continuação da conversa}

Uma primeira ressalva a ser feita é que, ao longo do texto, foram utilizados os termos TAs, AN e BN como descritores das pessoas atendidas pelo serviço, considerando-se a legitimação desses diagnósticos para a estruturação do tratamento oferecido e das inteligibilidades construídas nas práticas em saúde ofertadas nesse contexto local. Todavia, a partir do discurso construcionista social, entendemos que qualquer nomeação do que venha a ser entendido como uma alimentação adequada nasce de acordos sociais, históricos e contextuais. Por essa razão, consideramos o diagnóstico uma construção social e não uma verdade absoluta sobre o que acontece com essas pessoas ou sobre quem elas são. Ainda, considerando-se os prejuízos que o discurso do diagnóstico pode acarretar ao essencializar e cristalizar um modo de ser patológico nas pessoas diagnosticadas, defendemos a exploração de versões alternativas. Ao mesmo tempo, sabemos que o diagnóstico, nos contextos contemporâneos de produção de sentidos em saúde, é muitas vezes considerado fundamental para que as pessoas se sintam cuidadas, ou seja, oferecer um nome para o sofrimento vivido parece ser de alguma ajuda, trazendo certo alívio pelo menos em um primeiro momento.

Outro ponto de destaque relaciona-se ao fato de que, ainda que o objetivo da entrevistadora fosse a exploração de aspectos positivos no relacionamento profissional-família, os entrevistados também relataram aspectos que julgam faltar nessa relação. Entendemos ser importante o reconhecimento de que, em que certa medida, estudos apreciativos em contextos como os de saúde, nos quais uma retórica de denúncia relaciona-se a possibilidade de defesa dos direitos dos usuários, não são limitados nem questionáveis em sua utilidade.

A partir da análise aqui empreendida, defendemos práticas de atendimento em TAs que partilhem, entre profissionais e usuários, o poder sobre as decisões no tratamento, como outros países já o fazem, no caso dos TAs, e, como foi visto na introdução deste estudo. Isso pode se dar com a participação do usuário e do familiar nas reuniões de equipe ou com conversas nas quais todos têm igual oportunidade de interpretação sobre o que está ocorrendo com a pessoa assistida. Um questionamento que nos parece importante é: em que medida o ambiente hospitalar e sua estrutura de funcionamento impedem que essas conversas aconteçam, por cristalizar o papel do profissional como protagonista único dos rumos do tratamento? A possibilidade de atendimentos fora desse contexto tem sido explorada em países europeus e nos Estados Unidos já há algumas décadas.

Por fim, entendemos ser útil, ao avaliar todo e qualquer desafio no tratamento dos TAs em nosso país, refletir também sobre em que proporção a postura profissional impede a adesão do usuário e sua família ou os mantém em um lugar de desempoderados e dependentes. Aqui, buscamos provocar essa corresponsabilização, além de tocar no tema tabu de questionar se as teorias científicas sobre os TAs, e poderíamos incluir muitas outras psicopatologias, têm realmente levado à melhora que almejamos.

Os resultados obtidos sugerem a importância de desenvolver estudos futuros com foco nos aspectos apreciados por familiares e profissionais sobre o relacionamento construído entre eles.

\section{REFERÊNCIAS}

American Psychiatric Association. (2006). Practice guideline for the treatment of patients with eating disorders. Washington DC: Author.

Anderson, H. (1997). Conversation, language, and possibilities: A postmodern approach to therapy. New York: Basic Books, 1997.

Brasil. Ministério da Saúde. (2009). O SUS de A a Z : Garantindo saúde nos municípios. Brasília: Editora do Ministério da Saúde.

Campos, L. K. S., Sampaio, A. B. R. F., Garcia Junior, C., Magdaleno Junior, R., Battistoni, M. M. M., \& Turato, E. R. (2012). Características psicológicas de mães de pacientes com anorexia nervosa: Implicações para o trata- 
mento e prognóstico. Trends Psychiatry Psychotherapy, 34(1), 13-18.

Couturier, J., Isserlin, L., \& Lock, J. (2010). Family-based treatment for adolescents with anorexia nervosa: A dissemination study. Eating Disorders, 18:199-209.

DoH. (2001). The expert patient: A new approach to chronic disease management for the twenty-first century. London: Department of Health.

Eisler, I. (2013). Family therapy for adolescent eating disorders: A special form of therapy or family therapy with a specific focus? Journal of Family Therapy, 35, 1-2.

Fleminger, S. (2005). A model for the treatment of eating disorders of adolescents in a specialized centre in The Netherlands. Journal of Family Therapy, 27(2), 147-157.

Honey, A., \& Halse, C. (2005). Parents dealing with anorexia nervosa: Actions and meanings. Eating Disorders, 13(4), $353-367$.

Jaeger, M. A. S., Seminotti, N., \& Garcia, F. O. (2011). O grupo multifamiliar como recurso no tratamento dos transtornos alimentares. Revista de Psiquiatria, 33(1), 2027.

Le Grange, D., Crosby, R. D., Rathouz, P. J., \& Leventhal, B. L. (2007). A randomized controlled comparison of family-based treatment and supportive psychotherapy for adolescent Bulimia Nervosa. Archives of General Psychiatry, 64(9), 1049-1056.

Lock, J. (2010). Treatment of adolescente eating disorders: Progress and Challenges. Minerva Psichiatry, 51(3), 207216.

Lock, J., Le Grange, D., Agras, W. S. \& Dare, C. (2001). Treatment manual for anorexia nervosa. London: The Guilford Press.

McNamee, S., \& Hosking, D.M. (2012). Research and social change: A relational constructionist approach. New York/Oxford: Routledge.

National Collaborating Centre For Mental Health. (2004). National clinical practice guideline: Core interventions in the treatment and management of anorexia nervosa bulimia nervosa, and related eating disorders. Londres: National Institute for Clinical Excellence.

Poser, M. (2005). Anorexia nervosa: A parent's perspective. Journal of Family Therapy, 27(2), 144-146.

Reed, J. (2007). Appreciative inquiry: Research for change. London: Sage Publications.
Smith, G. (2004). Anorexia and bulimia in the family: One parent's practical guide to recovery. London: Wiley.

Souza, L. V., \& Santos, M. A. (2009). A construção social de um grupo multifamiliar no tratamento dos transtornos alimentares. Psicologia: Reflexão e Crítica, 22(3), 317 326.

Souza, L. V., \& Santos, M. A. (2010). A participação da família no tratamento dos transtornos alimentares. Psicologia em Estudo, 15(2), 285-294.

Souza, L. V., McNamee, S., \& Santos, M. A. (2010). Avaliação como construção social: Investigação Apreciativa. Psicologia \& Sociedade, 22(3), 598-607.

Spink, M. J., \& Lima, H. (2013). Produção de sentidos no cotidiano: Uma abordagem teórico metodológica para análise das práticas discursivas. In M. J. Spink (Org.), Práticas discursivas e produção de sentidos no cotidiano: Aproximações teóricas e metodológicas (2 ed) (pp. 22 41). Rio de Janeiro: Centro Edelstein de Pesquisa Sociais.

Spink, M. J., \& Medrado, B. (2013). Produção de sentidos no cotidiano: Uma abordagem teórico metodológica para análise das práticas discursivas. In M. J. Spink (Org.), Práticas discursivas e produção de sentidos no cotidiano: Aproximações teóricas e metodológicas (2 ed) (pp. 7199). Rio de Janeiro: Centro Edelstein de Pesquisa Sociais.

Tierney, S. (2005). The treatment of adolescent anorexia nervosa: A qualitative study of the views of parents. Eating Disorders, 13(4), 369-379.

Treasure, J., Whitaker, W., Whitney, J., \& Schmidt, U. (2005). Working with families of adults with anorexia nervosa. Journal of Family Therapy, 27(2), 158-170.

Valdanha, E. D., Scorsolini-Comin, F., Peres, R. S., \& Santos, M. A. (2013). Influência familiar na anorexia nervosa: Em busca das melhores evidências científicas. Jornal Brasileiro de Psiquiatria, 62(3), 225-233.

Van Langenhove, L., \& Harré, R. (1999). Introducing positioning theory. In R. Harré, \& L. Van Langenhove (Eds.), Positioning theory (pp. 14-31). Oxford: Blackwell Publishers.
Recebido em: 01/10/2012 Primeira decisão editorial em: 03/09/2015 Aceito em: 23/01/2016 